\title{
THE INFLUENCE OF TEMPERATURE UPON VENOUS PRESSURE IN THE FOOT
}

\author{
By J. P. HENRY and O. H. GAUER \\ (From the Acro Medical Laboratory, Air Materiel Command, Wright-Patterson Air \\ Force Base, Dayton, Ohio)
}

(Submitted for publication June 25, 1949; accepted, March 13, 1950)

\section{INTRODUCTION}

If the venous pressure in the foot of a standing man were solely determined by the length of the hydrostatic column extending from the heart to the foot, it would approximate $100 \mathrm{~mm}$. Hg. However, the valves in the deep veins of the leg combine with the muscles to form a pump which is actuated by every movement of the limbs (1-3), and the venous pressure in the feet depends on the balance struck between the rate of removal of blood by this mechanism and the rate at which it is supplied by the arteries. If the activity of the leg remains approximately constant, venous pressure in the foot will depend upon the blood supply to it and, because the blood supply to the foot is greatly affected by the environmental temperature, temperature should be expected to play an important part in determining the mean venous pressure in the lower extremity.

\section{METHODS}

\section{Venous pressure measurements}

Twelve adult male subjects were employed. In all, the distance from heart to foot was of the order of 130 cms. In each case pressures were directly determined by inserting a needle into a dorsal vein of the foot. The vein was first rendered prominent by heating the foot and the needle was then inserted while the subject stood erect. In most cases it was of the double Lindemann type consisting of a blunt outer sheath and a removable pointed inner introducing needle (4). A simple glass tube manometer filled with normal saline solution containing heparin as an anti-coagulant was attached to the needle and the pressure determined by direct measurement of the vertical distance from the foot to the meniscus. In other cases a small inductance type manometer, designed for intracardiac use, was attached to the needle and pressure recordings made with an oscillographic camera (5). In two experiments fine vinylite tubing was threaded into the vein up to the ankle region through a 17 gauge needle. ${ }^{1}$ When the needle was re-

1 The authors wish to thank Mr. O. Schwidetsky of the Becton Dickinson Company for supplying the tubing and needle. moved, this tubing provided a comfortable, flexible connection between the vein and the miniature manometer. The latter was attached to the foot permitting unimpeded walking movements.

The saline manometer gave a reading of mean venous pressure. The inductance manometer registered the details of fluctuation during movement and planimetry of these curves gave the mean venous pressure.

Pressures were measured both when executing standing-walking and when standing relaxed and at ease, but not supported and without restriction of normal "fidgeting" movements. The standing-walking was carried out by transferring the weight from one foot to the other, without raising the heel from the ground, at a constant rate of $30 / \mathrm{min}$. for the experimental foot. In one series of experiments, elevation of the legs by a tilt-table was used to empty the veins more completely than would be possible by muscular action. The subjects were placed on the tilt-table in a horizontal position which was then rapidly swung into the vertical head-up posture. This gave an indication of the rate at which the veins filled after they had been almost completely emptied.

\section{Temperature adjustments}

The temperature of the feet was changed by two methods. In one, a foot bath was used which, when hot, was $40-45^{\circ}$ C. and, when cool, $18-22^{\circ}$ C. In the other, an air-conditioned room was employed, and its temperature could be changed from 0 to $55^{\circ} \mathrm{C}$. at any desired rate. First, shivering was induced, then a progressive increase in the temperature in five to six steps, each lasting 30 to 45 minutes, permitted the measurement of a series of responses grading from the full vasoconstriction of cold to marked vasodilation with profuse sweating. On some occasions the order was reversed and heating preceded the cooling. This did not affect the results.

\section{Blood flow assessment}

Blood flow in the feet was indirectly assessed in the air-conditioned room by measuring foot temperature with a thermocouple on the great toe of each foot. Observations were made at 10 to 15 minute intervals throughout the experiment. Fetcher, Hall, and Shaub (6) have shown that although such measurements are a poor index of flow when the environmental temperature approximates or exceeds that of the body, they are a good measure at lower environmental temperatures. Other clinical indices of vasodilation could be used at the higher temperatures, including the visible distension of the veins, red- 
ness of the skin, and the lassitude, the discomfort and profuse sweating of the subject. When local heat was employed blood oxygen content was measured by the technique of Van Slyke and Neill (7), since in the resting limb it constitutes an index of blood flow (8).

No attempt was made to induce fine changes in vasomotor adjustment because the experiments were solely designed to determine whether there was any significant difference between the behavior of the venous pressure in the foot when it was vasoconstricted and vasodilated and to contrast these pressures with those in the comfort state.

\section{RESULTS}

\section{Experiment I: Venous pressures after tilting into the erect posture}

Three trained subjects were each submitted to two tilt-table experiments in the air-conditioned room. Each test used the full range of response from shivering to sweating, and repeated tilts were made at various foot temperatures. At any given temperature there were considerable individual variations in the rate of rise of the venous pressure. Nevertheless, all the data obtained from these broad ranges of foot temperature were pooled into three groups corresponding to the hot vaso- dilated, the comfortable, and the cool shivering states (Figure 1). These groups gave three different rates of venous pressure increase. The results show that at toe temperatures in the range $39-36^{\circ} \mathrm{C}$., corresponding to sweating, the venous pressure will, after tilting, assume $80 \%$ or more of the full hydrostatic head in less than 30 seconds. However, when comfortable, that is, at a toe temperature of $36-28^{\circ} \mathrm{C}$., this value is not attained for one to two minutes and, when cold, at toe temperatures of $28-19^{\circ} \mathrm{C}$., the full potential pressure is not attained in three minutes of the test.

\section{Experiment II: Venous pressure during standing- walking}

The series of records shown in Figure 2 demonstrate the effect of walking upon venous pressure in the foot. The mechanism of the fluctuations in pressure that occur with a single step has recently been discussed by Pollack and Wood (9). They have pointed out that, within broad limits, the extent of venous pressure reduction is the same regardless of the rate or degree of muscular activity. In the record $\mathrm{A}$ of Figure 2 taken when the sub-

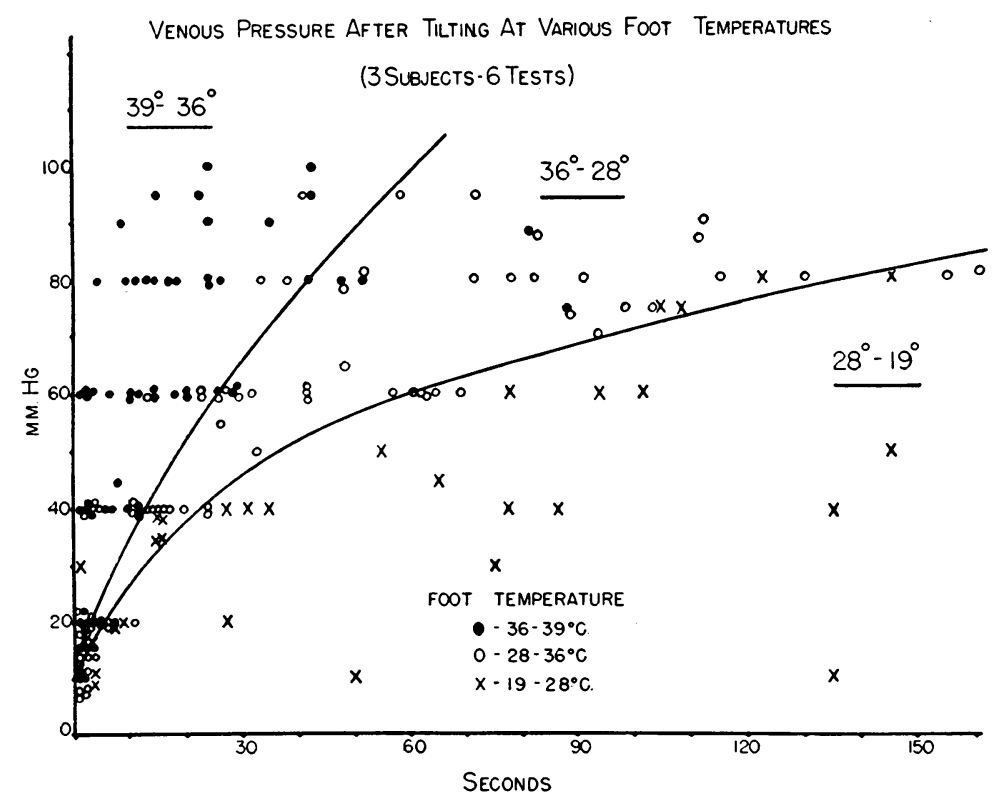

Fig. 1. Venous Pressure in the Foot at Various Time Intervals after Tilting from the Recumbent into the Erect Posture

Data from three subjects in six tests. The results are plotted for foot temperature ranges: $39-36^{\circ} \mathrm{C}$. ; $36-28^{\circ} \mathrm{C}$. ; $28-19^{\circ} \mathrm{C}$; they correspond respectively to the subjective sensations of sweating, comfortable and shivering. 


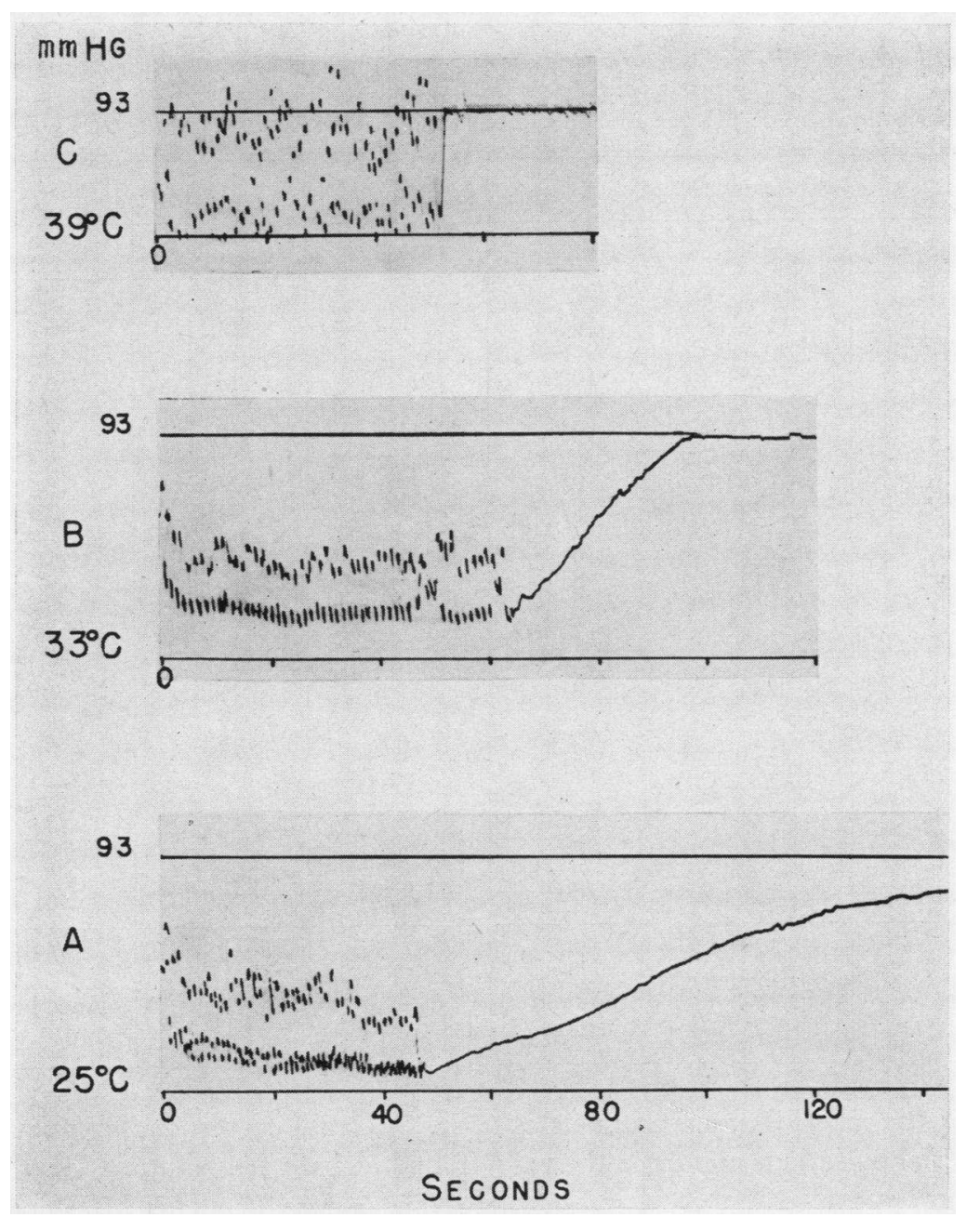

Fig. 2. Records of Venous Pressure in the foot at Various Toe Temperatures during Walking and Then Standing Still

A. At $25^{\circ}$ C.: There is a marked fall of the venous pressure with activity and when standing it rises slowly and does not attain the full hydrostatic head of $93 \mathrm{~mm}$. $\mathrm{Hg}$.

B. At $33^{\circ} \mathrm{C}$.: The depression of the venous pressure with activity is less marked, the rate of rise is faster. The full hydrostatic head is attained in 40 seconds.

C. At $39^{\circ}$ C.: The mean pressure is even higher, the return to the full hydrostatic head is very rapid and arterial pulsations are visible during quiet standing.

ject was cold, the time interval between the steps was too short to permit filling of the reservoir and mean pressure is low. Even when comfortable (Figure 2B), there was a considerable fall of mean pressure. However, when full vasodilation had occurred, then inflow was so rapid that the mean pressure rose (Figure 2C) toward the full resting value.
The second part of each record in Figure 2 shows the rate at which venous pressure rises during sudden immobility. The curves are similar to the dividing lines between the sectors in Figure 1. The slow rise when the foot is cool (Figure 2A) contrasts sharply with the precipitous return to full pressure when the vessels are dilated (Figure 2C). It is of interest that when the subject is 
TABLE I

Venous pressure in centimeters of water as measured by a saline tube manometer when standing as still as possible in the erect posture and when performing standing-walking.

First series measured with the foot in the bath at $40-45^{\circ} \mathrm{C}$., second series at $18-22^{\circ} \mathrm{C}$.

\begin{tabular}{|c|c|c|c|c|c|c|c|}
\hline \multicolumn{5}{|c|}{ Series I, temperature $40-45^{\circ} \mathrm{C}$. } & \multicolumn{3}{|c|}{ Series II, temperature $18-22^{\circ} \mathrm{C}$. } \\
\hline Subject & Exp. No. & Still & Exercise & Venous $\mathrm{O}_{2}$ & Still & Exercise & Venous $\mathrm{O}_{2}$ \\
\hline 1 & 1 & $\begin{array}{l}c m s \\
124\end{array}$ & $\begin{array}{r}\text { cms. } \\
90\end{array}$ & $\begin{array}{c}\text { Vols. \% } \\
\text { - }\end{array}$ & $\begin{array}{l}\text { cms. } \\
112\end{array}$ & $\begin{array}{c}\text { cms. } \\
51\end{array}$ & $\begin{array}{c}\text { Vols. \% } \\
-\end{array}$ \\
\hline 2 & 2 & 150 & 102 & 17.7 & 144 & 33 & - \\
\hline 3 & 3 & 127 & 94 & 14.4 & 123 & 61 & 8.0 \\
\hline 2 & $\begin{array}{l}4 \mathrm{a} \\
4 \mathrm{~b}\end{array}$ & $\begin{array}{l}135 \\
145\end{array}$ & $\begin{array}{r}99 \\
102\end{array}$ & - & $\begin{array}{l}119 \\
119\end{array}$ & $\begin{array}{l}38 \\
38\end{array}$ & - \\
\hline 1 & $\begin{array}{l}5 \mathrm{a} \\
5 \mathrm{~b}\end{array}$ & $\begin{array}{l}123 \\
122\end{array}$ & $\begin{array}{l}97 \\
94\end{array}$ & 17.8 & 121 & 46 & 10.0 \\
\hline 4 & 6 & 135 & 112 & - & 132 & 64 & - \\
\hline 5 & 7 & 126 & 91 & 17.2 & 125 & 61 & 9.4 \\
\hline 6 & $\begin{array}{l}8 \mathrm{a} \\
8 \mathrm{~b}\end{array}$ & $\begin{array}{l}122 \\
122\end{array}$ & $\begin{array}{l}97 \\
91\end{array}$ & 16.8 & 122 & 66 & 12.7 \\
\hline 7 & $\begin{array}{l}9 \mathrm{a} \\
9 \mathrm{~b}\end{array}$ & $\begin{array}{l}122 \\
122\end{array}$ & $\begin{array}{l}81 \\
89\end{array}$ & 16.3 & 122 & 53 & 9.5 \\
\hline 8 & 10 & 131 & 99 & 15.9 & 130 & 61 & 8.7 \\
\hline \multicolumn{2}{|c|}{ Average mean } & 129 & 96 & 16.5 & 125 & 52 & 9.7 \\
\hline \multicolumn{2}{|c|}{$\begin{array}{l}\text { Approximate levels on } \\
\text { average subjects }\end{array}$} & Heart level & $\begin{array}{l}\text { Inguinal } \\
\text { region }\end{array}$ & & & Knee level & \\
\hline
\end{tabular}

hot, the dilation of the arteriovenous channels is so marked that arterial pulsations appear in the venous pressure record.

\section{Experiment III: Mean venous pressure during standing-walking ${ }^{2}$}

The preceding experiment demonstrated the difference in the fluctuations of venous pressure when performing standing-walking during various states of vasodilation. If a saline filled manometer tube is used under these conditions its response will be so slow that it will record mean pressures.

Table I presents the mean pressures as determined in 10 experiments on eight subjects when cooling and heating the foot in a water bath. There is a clear difference between the mean level of $52 \mathrm{cms}$. approximating knee height, obtained when the foot is cooled in the bath at $18-22^{\circ} \mathrm{C}$., and

2 An abstract of this work, which was performed by one of us (JPH) at the University of Southern California, appears in the American Journal of Medicine, 1948, 4, 618. the $96 \mathrm{cms}$. corresponding to the inguinal level found at bath temperatures of $40-45^{\circ} \mathrm{C}$.

The oxygen content of venous samples taken while resting, and so minimally contaminated by muscle blood, differed markedly in the hot and cool tests because of the difference in blood flow. If a mean oxygen content of 21 vols. $\%$ is assumed for arterial blood, then the arteriovenous oxygen difference falls with heating from 21 less 10 vols. \%., or 11 vols. \%, to 21 less 17 vols. \%, or 4 vols. $\%$. Although these approximate figures suggest a two- to three-fold increase in blood flow, they probably underestimate the true change. Correction for the difference in tissue metabolism at the two temperature extremes and for the failure to induce severe vasoconstriction by local cooling would add to the figure and bring it closer to other observations. Thus, Love (10) has recently demonstrated a five-fold increase in foot blood flow when passing from the vasoconstricted to the vasodilated state. 
Experiment IV:Venous pressure changes in the foot during relaxed, quiet standing

The preceding experiments show that temperature-induced changes in blood flow to the feet will greatly affect the mean level of venous pressure during an activity such as walking. It might be thought that such an effect would play little part in determining mean venous pressure when at rest. However, as Hellebrandt, Crigler and Kelso (11) point out, the term "at rest" is a misnomer and even quiet standing is "movement on a fixed base." In fact, unless a deliberate attempt is made to inhibit them, overt movements, such as shifting of the weight from one foot to the other, occur at least once a minute in persons standing quietly at ease. Experiment I demonstrated that at comfortable environmental temperatures it takes longer than one minute to refill the venous reservoir. Therefore, a study of the mean venous pressure during such quiet standing should show
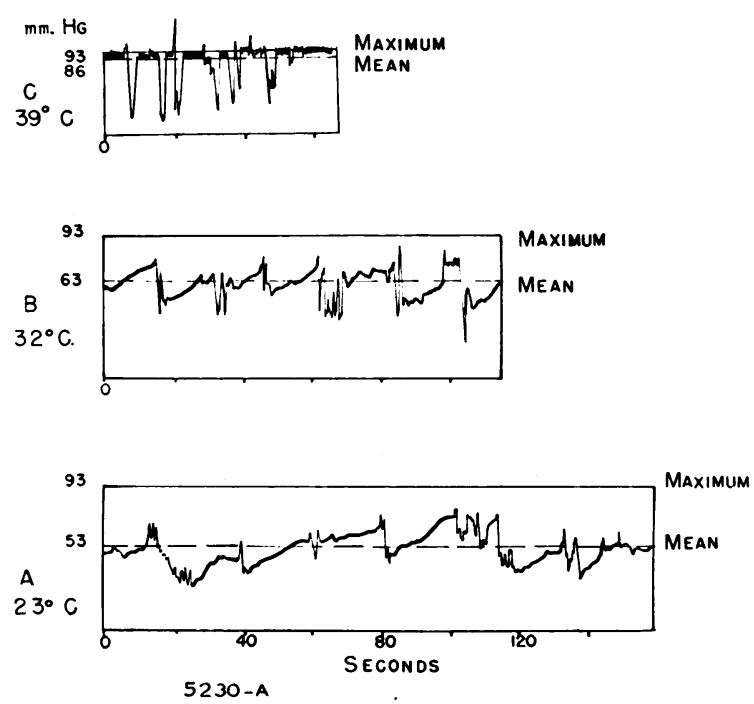

Fig. 3. Records of Venous Pressure in the Foot When Standing at Ease at Various Ambient TemPERATURES

A. Venous pressure when chilly with a toe temperature of $23^{\circ} \mathrm{C}$. The rise of venous pressure after each series of movements is comparatively slow, resulting in low mean pressure.

B. Venous pressure when comfortable with a toe temperature of $32^{\circ} \mathrm{C}$. The pressure rises more rapidly after each movement and the mean pressure is higher.

C. Venous pressure when hot showing the marked pulsation accompanying vasodilation. After movement the pressure rapidly returns to its full value and the mean is very close to the full hydrostatic head of $93 \mathrm{~mm}$. $\mathrm{Hg}$.

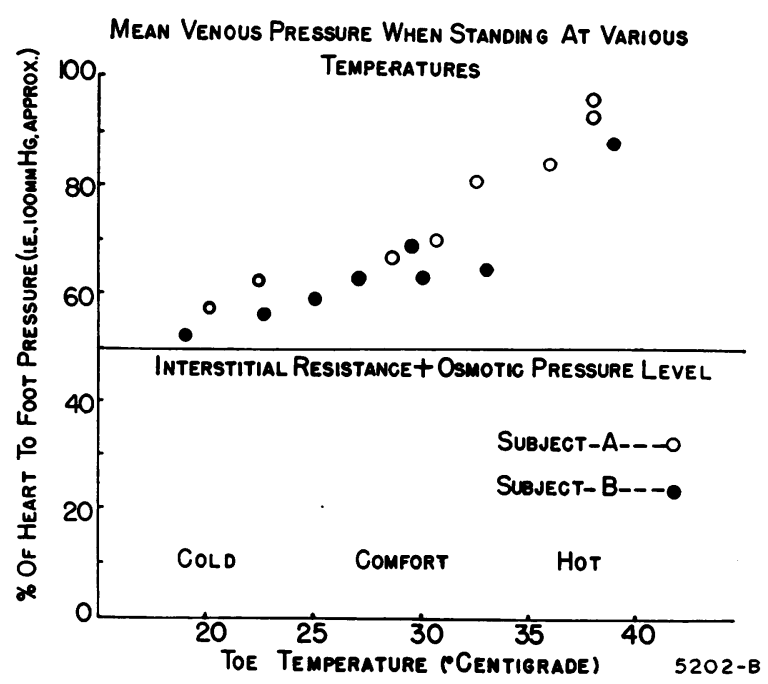

Fig. 4. Estimations of Mean Venous Pressure in Foot at Various Toe Temperatures When Standing Quietly

As temperature increases, the mean venous pressure rises until when the subject is hot it greatly exceeds the pressure opposing filtration.

interesting changes with temperature. Two subjects were observed while standing at ease in the air-conditioned room under various conditions of environmental temperature. Figure 3 shows typical records. Although gross muscular movements, such as shifting of the feet, occurred just as frequently when the subject was hot as when cold, the mean venous pressure as determined by planimetry differed widely at the various temperatures. Thus when cold it was $53 \mathrm{~mm}$. $\mathrm{Hg}$, or $57 \%$, of the full potential value (Figure $3 \mathrm{~A}$ ). With warming to the comfort zone, the level rose to $63 \mathrm{~mm}$. $\mathrm{Hg}$, or $68 \%$, of the full value (Figure $3 \mathrm{~B}$ ). Full heat vasodilation raised the mean level to $86 \mathrm{~mm}$ $\mathrm{Hg}$, or $92 \%$, of the hydrostatic head from heart to foot (Figure 3C). These curves show repeated abrupt falls in pressure coinciding with movement, followed by rises whose slope is proportional to the blood flow at that particular temperature. Thus, in effect, they represent an irregular combination of a series of curves of the type shown in Figure 2.

Planimetric determination of the mean pressure during representative periods of standing at various toe temperatures yields a series of values for each subject which are separately recorded in Figure 4. The resultant coordinates describe a 
curve relating mean pressure in the foot when standing at ease to toe temperature. The combined interstitial tissue pressure in the skin of the foot and osmotic pressure of the plasma proteins are probably not greater than $50 \mathrm{~mm}$. $\mathrm{Hg}$ (Figure 4) $(12-15)$. It is interesting that venous pressure in the foot only exceeds these balancing pressures by approximately $10 \mathrm{~mm}$. $\mathrm{Hg}$ in the cold and comfortable zones. However, with the onset of vasodilation, the disparity between intravascular pressure and the force available to balance it increases until, when hot and sweating, there is an excess of pressure of more than $40 \mathrm{~mm}$. $\mathrm{Hg}$ within the minute vessels.

\section{DISCUSSION}

These observations help to explain the swelling of dependent regions such as the ankles, so often noted in hot weather (16). Local increases in capillary pressure and filtration area due to heat vasodilation play their part in the production of heat edema (17). However, the gravity-conditioned distribution of the edema suggests that these are not the only factors. This work has shown that, when erect, venous pressure in the ankles is greatly increased during vasodilation. The rate of fluid accumulation at pressures of 80-100 mm. Hg may well exceed the capacity of the lymphatics to remove it (18).

The incidence of dependent heat edema may be more frequent whenever, as in the case described by Hardy, Milhorat, and DuBois (19), excessive vasodilation occurs in response to heat stress. The obese who must dissipate heat by vasodilation rather than by conduction through the superficial body layers, and those who cannot sweat normally, as may be the case in congestive heart failure (20), may be expected to show an increased incidence of heat edema.

Heat edema may also occur when inactivity decreases the pumping effect of the muscles. Brull (21) has pointed out that when normal persons are forced to remain immobile for long periods they will develop severe edema. Smirk (22) has suggested that there may be a decrease in voluntary activity in early congestive heart failure and that this may play some part in the development of edema in cases of ambulatory heart disease. Certainly there are occasions when the factors of impaired electrolytic balance (23), decreased os- motic pressure (22) or increased central venous pressure $(24,20)$ cannot be invoked to explain the development of cardiac edema (25). On the other hand, it is known that cases of heart disease develop ankle edema more frequently in hot weather (26). Finally, the frequency with which varicose ulcers and other chronic disturbances of the legs develop in the southern states may be, in part, associated with persistent vasodilation in these hot humid regions (27). It is of interest in this connection that vasodilation may lead to incompetency of venous valves which are adequate in the vasoconstricted state (28).

\section{SUMMARY}

1. Venous pressure in the foot when in the erect posture is a resultant of the relative rates at which blood flows into the veins from the arteries and is removed from them by muscular activity.

2. In adults, during vasodilation induced by heat, even vigorous walking movements fail to reduce the mean venous pressure below $70 \mathrm{~mm}$. $\mathrm{Hg}$. However, when in the comfort zone, far less activity is required to effect such a reduction. Finally, when cool, even normal involuntary postural movements will reduce venous pressure to $50 \mathrm{~mm} . \mathrm{Hg}$. This level approximates that of the counter-balancing osmotic and tissue pressures.

3. The increase in venous pressure that results from vasodilation can play a part in the development of edema of the extremities.

\section{BIBLIOGRAPHY}

1. Heller, R. E., Circulation in normal and varicose veins. Surg., Gynec. \& Obst., 1942, 74, 1118.

2. Beecher, H. K., Field, M. E., and Krogh, A., A method for measuring venous pressure in the human leg during standing. Skandinav. Arch. f. Physiol., 1936, 73, 7.

3. Beecher, H. K., Field, M. E., and Krogh, A., The effect of walking on venous pressure at the ankle. Skandinav. Arch. f. Physiol., 1936, 73, 133.

4. Henry, J. P., Greeley, P. O., Fryckman, V. L., and Peterson, L., An indwelling needle made for use in the radial artery. Science, 1946, 104, 299.

5. Gauer, O. H., and Gienapp, E., A miniature manometer for physiological recording. Science (To be published).

6. Fetcher, E. S., Hall, J. F., and Shaub, H. G., Skin temperature as an index to blood flow. USAF Air Materiel Command. Memo., Rpt. No. MCREXD696-113S, Mar. 22, 1949. 
7. Van Slyke, D. D., and Neill, J. M., The determination of gases in blood and other solutions by vacuum and manometric methods. J. Biol. Chem., 1924, 61, 523.

8. Goldschmidt, S., and Light, A. B., Effect of local temperature and peripheral circulation with metabolism of tissues as revealed by the gaseous content of venous blood. Am. J. Physiol., 1925, 73, 146.

9. Pollack, A. A., and Wood, E. H., Venous pressure in the saphenous vein at the ankle in man during exercise and changes in posture. J. Applied Physiol., 1949, 1, 649.

10. Love, L., Heat loss and blood flow of the feet under hot and cold conditions. J. Applied Physiol., 1948, $1,20$.

11. Hellebrandt, F. A., Crigler, E. F., and Kelso, L. E. A., Variations in intramuscular pressure during postural and phasic contraction of human muscle. Am. J. Physiol., 1939, 126, 247.

12. Burch, G. E., and Sodeman, W. A., The estimation of the subcutaneous tissue pressure by a direct method. J. Clin. Invest., 1937, 16, 845.

13. Wells, H. S., Youmans, J. B., and Miller, D. G., Jr., Tissue pressure (intracutaneous, subcutaneous and intramuscular) as related to venous pressure, capillary filtration, and other factors. J. Clin. Invest., 1938, 17, 489.

14. McMaster, P. D., Conditions in the skin influencing interstitial fluid movement, lymph formation and lymph flow. Ann. New York Acad. Sc., 1946, 46, 743.

15. Youmans, J. B., Wells, H. S., Donley, D., and Miller, D. G., The effect of posture (standing) on the serum protein concentration and colloid osmotic pressure of blood from the foot in relation to the formation of edema. J. Clin. Invest., 1934, 13, 447.

16. Castellani, A., Minor tropical diseases. Tr. Roy. Soc. Trop. Med. \& Hyg., 1931, 24, 379.
17. Landis, E. M., and Gibbon, J., Jr., The effects of temperature and of tissue pressure on the movement of fluid through the human capillary wall. J. Clin.. Invest., 1933, 12, 105.

18. Landis, E. M., Jonas, L., Angevine, M., and Erb, W., The passage of fluid and protein through the capillary wall during venous congestion. J. Clin. Invest., 1932, 11, 717.

19. Hardy, J. D., Milhorat, A., and DuBois, E., Basal metabolism and heat loss of young women at temperatures of $22-35^{\circ} \mathrm{C}$. J. Nutrition, 1941, 21, 383.

20. Burch, G., Influence of environmental temperature and relative humidity on the rate of water loss through the skin in congestive heart failure in subtropical climates. Am. J. M. Sc., 1946, 211, 181.

21. Brull, L., L'oedème des évacués de 1940 . Acta clin. belg., 1946, 1, 268.

22. Smirk, F. H., Observations on the causes of oedema in congestive failure. Clin. Sc., 1936, 2, 317.

23. Futcher, P. H., and Schroeder, H., Studies on congestive heart failure, impaired renal excretion of sodium chloride. Am. J. M. Sc., 1942, 204, 52.

24. Dock, W., Congestive heart failure. Adaptation of the body to inadequate cardiac output. J.A.M.A., 1949, 140, 1135.

25. Foote, S. A., Jr., Reed, W. C., Comeau, W. J., and White, P. D., Clinical significance of bilateral edema of the lower extremities. Am. J. M. Sc., 1940, 199, 512.

26. Harrison, T. R., Failure of the Circulation. Williams \& Wilkins, Baltimore, 1939, Ed. 2, p. 327.

27. Mahorner, H., Indurated leg and leg ulcers. A clinical study of their etiology and treatment. Surg., Gynec. and Obst., 1949, 88, 115.

28. Franklin, K. J., A Monograph on Veins. C. C. Thomas, Springfield, Ill., 1937, p. 77. 